\title{
Validation of a Patient Satisfaction Scale in Patients Undergoing Bowel Preparation Prior to Colonoscopy
}

\author{
Hind T. Hatoum ${ }^{1,2} \cdot$ Swu-Jane $\operatorname{Lin}^{2} \cdot$ Raymond E. Joseph ${ }^{3} \cdot$ David N. Dahdal $^{3}$
}

Published online: 29 December 2015

(C) The Author(s) 2015. This article is published with open access at Springerlink.com

\begin{abstract}
Background Colonoscopy is the most widely used test to screen for colorectal cancer but its use may be hindered by patients' inability to complete the bowel preparation. Patient-reported satisfaction with bowel-cleansing preparations has received little attention. We assessed the reliability and validity of a patient satisfaction survey used in two large, multicenter, randomized, assessor-blinded colonoscopy trials.

Methods Datasets from two pivotal trials were combined. Patients in both trials included men and women aged 18-80 years who were scheduled for an elective outpatient colonoscopy. Questions relevant to satisfaction with bowel preparation prior to colonoscopy were identified from the literature and incorporated into a 7-item survey administered to patients on the day of colonoscopy. Domain 1 of the satisfaction measure assessed difficulty using bowelcleansing preparations, ability to consume preparations, acceptability of taste, and overall experience; questions regarding acceptance or refusal of future use of the same bowel preparation were asked in Domain 2. Responses from each item of Domain 1 were transformed on a scale ranging from 0 to 100 and summed as total satisfaction scores. Cronbach's alpha was used to measure reliability; validity was assessed by evaluating relationship between total satisfaction (Domain 1) and willingness to use preparation in the future (Domain 2).
\end{abstract}

Hind T. Hatoum

hthatoum@sbcglobal.net

1 Hind T. Hatoum \& Company, 155 N Harbor Drive, \#1912, Chicago, IL 60601, USA

2 University of Illinois at Chicago, Chicago, IL, USA

3 Ferring Pharmaceuticals Inc., Parsippany, NJ, USA
Results Mean age of the 1211 trial participants was 56: $61 \%$ female, $89.5 \%$ Caucasian. Domain 1 had a Cronbach's alpha of 0.79 , with higher satisfaction predicting higher future acceptability $(p<0.0001)$.

Conclusion The patient-reported satisfaction measure of bowel-cleansing preparations possesses good validity and reliability.

\section{Key Points for Decision Makers}

The patient survey on the tolerability and satisfaction on the use of a precolonoscopy bowel-cleansing preparation is reliable and valid.

The patient satisfaction survey predicts patients' willingness to use bowel-cleansing preparation for future colonoscopy.

\section{Introduction}

Colonoscopy is a minimally invasive endoscopic examination of the colon widely used for the diagnosis and treatment of colon disorders [1]. It is the most commonly used test to screen for colorectal cancer (CRC); results from case-control studies suggest that colonoscopy is associated with a $50 \%$ reduction in CRC development [2] and a 60-67\% reduction in CRC deaths [3, 4]. However, adherence of the general population to CRC screening by colonoscopy is lower than expected [5] owing to fear of discomfort or complications, embarrassment, and 
unpleasant experience with precolonoscopy bowel-cleansing preparations $[6,7]$.

Patient-reported outcomes (PROs) are regarded as clinically important endpoints by regulatory agencies. The measurement of satisfaction is important in light of studies showing that satisfied patients are more likely to comply with prescribed treatments and maintain a relationship with a specific care provider [8]. A retrospective review of 15 studies on patient satisfaction with colonoscopy revealed that of those patients who had undergone colonoscopy, nearly $95 \%$ were very satisfied with the colonoscopy experience and 73-100\% were willing to repeat the procedure in the future [9]. However, most studies reporting on patients' satisfaction with colonoscopy have focused on the overall experience rather than specifically on the bowel-cleansing preparations.

In 2012, Prepopik ${ }^{\circledR}$ (Ferring Pharmaceuticals Inc., Parsippany, NJ, USA), a dual-action, non-phosphate, lowvolume bowel-cleansing preparation containing sodium picosulfate and magnesium citrate (P/MC), was approved by the US FDA based on results from the Safety and Efficacy of Dual-Action, Low-Volume Bowel Preparation: An Evaluation of Colon Cleansing in Day-Before and Split-Dose Regimens (SEE CLEAR) I and II trials $[10,11]$. In both trials, tolerability and satisfaction of the bowel preparation was assessed as a secondary endpoint using a PRO survey created by the clinicians who designed the SEE CLEAR trials $[10,11]$. The objective of the present study was to evaluate the reliability and validity of the patient satisfaction survey used in the pivotal trials. As part of the validity assessment, we evaluated the relationship between patient satisfaction and patients' self-reported willingness to accept the same bowel preparation agent for a future procedure.

\section{Materials and Methods}

\subsection{Data Source}

Patient demographics were similar across treatment groups in SEE CLEAR I and II [10, 11]; thus, data from SEE CLEAR I and II were combined in this current study (Table 1). The study designs of the two trials were identical, with the exception of the timing of P/MC administration, i.e. day-before versus split-dose administration. To be eligible for either study, patients were required to have had at least three spontaneous bowel movements per week for 1 month prior to the scheduled colonoscopy. Patients with renal insufficiency (serum creatinine clearance outside the normal range $[45-84 \mu \mathrm{mol} / \mathrm{L}$ for women and 59-104 $\mu \mathrm{mol} / \mathrm{L}$ for men]) and serum potassium outside the normal range (3.6-5.2 $\mathrm{mmol} / \mathrm{L})$ were excluded from the study. Patients with active inflammatory bowel disease, colonic disease, gastrointestinal disorders, or a previous colorectal or upper gastrointestinal surgery were also excluded. Additional details regarding study design and patient populations can be found in the full published reports $[10,11]$.

During the design of the SEE CLEAR studies, items relevant to a patient's experience with bowel cleansing were identified from a review of the literature, and were used to assemble the survey [12-16]. The survey consisted of seven unique questions that were separated into two domains for the present analysis: Domain 1 related to a patient's current satisfaction, and Domain 2 related to future willingness to use the same preparation (Table 2). The two domains were utilized to investigate the relationship between a patient's satisfaction with their current bowel preparation and the willingness to undergo bowel

Table 1 Patient demographics (ITT population)

\begin{tabular}{|c|c|c|c|c|}
\hline \multirow[t]{2}{*}{ Parameter } & \multicolumn{2}{|l|}{ SEE CLEAR I } & \multicolumn{2}{|l|}{ SEE CLEAR II } \\
\hline & $\begin{array}{l}\text { Split-dose } \\
\text { P/MC } \\
{[n=305]}\end{array}$ & $\begin{array}{l}\text { Day-before } \\
\text { 2-L PEG + bis } \\
{[n=298]}\end{array}$ & $\begin{array}{l}\text { Day-before } \\
\text { P/MC } \\
{[n=296]}\end{array}$ & $\begin{array}{l}\text { Day-before } \\
2-\mathrm{L} \text { PEG + bis } \\
{[n=302]}\end{array}$ \\
\hline Mean age, years (range) & $54.8(22-77)$ & $55.7(1-80)$ & $56.8(21-78)$ & $56.2(18-79)$ \\
\hline \multicolumn{5}{|l|}{ Age, years $[n(\%)]$} \\
\hline $18-64$ & $253(83)$ & $250(84)$ & $236(80)$ & $247(82)$ \\
\hline$\geq 65$ & $52(17)$ & $48(16)$ & $60(20)$ & $55(18)$ \\
\hline \multicolumn{5}{|l|}{$\operatorname{Sex}[n(\%)]$} \\
\hline Male & $124(41)$ & $124(42)$ & $104(35)$ & $113(37)$ \\
\hline Female & $181(59)$ & $174(58)$ & $192(65)$ & $189(63)$ \\
\hline Median BMI, kg/m² (range) & $29.4(18.3-49.8)$ & $29.6(16.6-54.4)$ & $29.19(17.5-45.5)^{\mathrm{a}}$ & $29.54(16.80-51.32)$ \\
\hline
\end{tabular}

BMI body mass index, ITT intent-to-treat, 2-L PEG + bis 2-L polyethylene glycol solution + two 5-mg bisacodyl tablets, $P / M C$ sodium picosulfate and magnesium citrate

${ }^{\text {a }} n=293$ patients as the measurements needed to calculate BMI at baseline were missing for some patients 
Table 2 Patient satisfaction survey measures

\begin{tabular}{|c|c|c|}
\hline & Item description & Rating \\
\hline \multirow[t]{4}{*}{$\begin{array}{l}\text { Domain } \\
1\end{array}$} & $\begin{array}{l}\text { 1. How easy or difficult was it to consume the } \\
\text { study drug? }\end{array}$ & $\begin{array}{l}\text { Very } \\
\text { easy } \\
\text { Easy } \\
\text { Tolerable } \\
\text { Difficult } \\
\text { Very } \\
\text { difficul }\end{array}$ \\
\hline & $\begin{array}{l}\text { 2. Were you able to consume the entire } \\
\text { preparation as instructed? }\end{array}$ & $\begin{array}{l}\text { Yes } \\
\text { No }\end{array}$ \\
\hline & $\begin{array}{l}\text { 3. Please describe your overall experience of } \\
\text { the study preparation: }\end{array}$ & $\begin{array}{l}\text { Excellent } \\
\text { Good } \\
\text { Fair } \\
\text { Poor } \\
\text { Bad }\end{array}$ \\
\hline & 4. The taste of this study preparation was: & $\begin{array}{l}\text { Excellent } \\
\text { Good } \\
\text { Tolerable } \\
\text { Poor } \\
\text { Bad }\end{array}$ \\
\hline \multirow[t]{2}{*}{$\begin{array}{l}\text { Domain } \\
2\end{array}$} & $\begin{array}{l}\text { 5. Would you ask your doctor for this } \\
\text { preparation again if you needed another } \\
\text { colonoscopy in the future? }\end{array}$ & $\begin{array}{l}\text { Yes } \\
\text { No }\end{array}$ \\
\hline & $\begin{array}{l}\text { 6. Would you refuse the same preparation } \\
\text { again if it were to be prescribed to you in the } \\
\text { future? }\end{array}$ & $\begin{array}{l}\text { Yes } \\
\text { No }\end{array}$ \\
\hline
\end{tabular}

preparation in a future colonoscopy. Domain 1 included four items assessing the ease or difficulty of consuming the bowel-cleansing preparation, whether the patient was able to consume the entire preparation, the taste of the preparation, and the overall experience when using the preparation. Patients reported on their ability to complete the entire preparation with a binary 'yes' or 'no' response. The three other questions in Domain 1 required patients to report satisfaction on a five-point scale (Table 2). Domain 2 included two additional 'yes/no' questions to assess participants' willingness to accept or refuse the same bowel preparation in a future colonoscopy. One final question (question 7) asked patients to report details of any prior colonoscopy and bowel preparation experience. As this final question did not relate to a patient's satisfaction with their current bowel preparation, question 7 was not included in the analysis. Bowel cleanse quality was rated by the endoscopist using a modified version of the Aronchick scale and the Ottawa scale. Patients were classified as responders (successful bowel cleansing) if the rating was 'excellent' or 'good' on the Aronchick scale [17], or 'excellent', 'good', or 'fair' on the Ottawa scale [12].

\subsection{Statistical Analyses}

The three items of Domain 1 with a five-point scale were assigned scores from 0 to 4 , with 0 representing the most favorable and 4 representing the least favorable answers; the dichotomous item was coded as 0 for yes and 1 for no. The raw score of each of the four items was then transformed to a range from 0 to 100 to standardize items. These values were then summed to generate a total satisfaction score between 0 and 400 , where a lower score indicates higher satisfaction. The total converted numerical scores were compared between patients receiving P/MC versus 2-L polyethylene glycol (PEG)-3350 and two 5-mg bisacodyl tablets (PEG + bis). In Domain 2, acceptability of the preparations was evaluated based on participants' responses as to whether they would accept or refuse the bowel-cleansing preparation for a future colonoscopy. Psychometric properties of the satisfaction survey, including internal consistency reliability (the degree to which individual questions within the survey are related to each other [18]) and validity (the degree to which an instrument is relevant to or valid in what it is purported to measure [19]) were evaluated. A survey of the literature conducted during the development of the questionnaire did not find an existing validated measure of patient satisfaction in patients undergoing bowel preparation prior to colonoscopy. In the present analysis, predictive validity was established by evaluating whether total satisfaction scores could predict a patient's willingness to accept or refuse the same bowel preparation for a future colonoscopy.

Cronbach's alpha was used to measure the internal consistency of patients' responses to the individual questions of Domain 1 of the satisfaction questionnaire. Values above 0.70 reflect acceptable reliability (internal consistency) [20]. The validity of the patient satisfaction instrument was assessed by determining the 'discrimination' and the 'predictive validity' of test scores. Discrimination was assessed by examining the extent of floor and ceiling effects, as measured by the percentages of responses at either end of the response range using the raw item scores (an item is considered to have a ceiling effect if most responses fall on its highest value) [21]. The distribution of responses to the four questions of Domain 1 were examined as to their possible ceiling/floor effects based on the criterion of $>15 \%$ of responses at the extreme end of the scale [22]. The predictive validity was determined by evaluating the relationship between the satisfaction scores (Domain 1) and the acceptability measure on the likelihood to accept the same preparation in the future (Domain 2). The relationship between transformed satisfaction scores and the proportions of responders and nonresponders, defined according to the trials' clinical endpoints, was also assessed; patients with 
incomplete satisfaction surveys or missing efficacy measurements were excluded from this analysis.

All continuous variables were checked for normality. Wilcoxon rank sum test was used for variables found to be non-normally distributed. Associations between total transformed satisfaction scores and willingness to use the preparation in the future, and between total transformed satisfaction scores and efficacy were analyzed by Wilcoxon rank sum test. All analyses were carried out using SAS 9.1 statistical software (SAS Institute, Inc., Cary, NC, USA).

\section{Results}

A total of 1211 patients were randomized to receive P/MC or PEG + bis across the two trials. Not all study participants completed the treatment or finished the entire satisfaction questionnaire; thus, the sample size used in this analysis was smaller than the 1211 patients who participated in the two trials. Six of the $608(0.98 \%)$ participants in the SEE CLEAR I study and 10 of the 603 (1.66\%) participants in the SEE CLEAR II study did not complete the patient satisfaction questionnaire and were excluded from the analysis. The mean age of the entire study population was 56 years, $61 \%$ were female, and $89.5 \%$ were Caucasian. Patient characteristics for the safety populations from SEE CLEAR I and II are shown in Table 1. The mean (standard deviation) transformed total satisfaction score of the entire study population was 97.2 (75.3), suggesting that most patients were satisfied with the study preparations; median score was 100 . The distribution of responses to each of the satisfaction survey questions in Domain 1 is shown in Fig. 1. The total transformed satisfaction score was significantly better for patients administered P/MC versus $\mathrm{PEG}+$ bis (median: $\mathrm{P} / \mathrm{MC}$ vs. $\mathrm{PEG}+$ bis, 50 vs. 120; $p<0.0001)$ (Table 3).

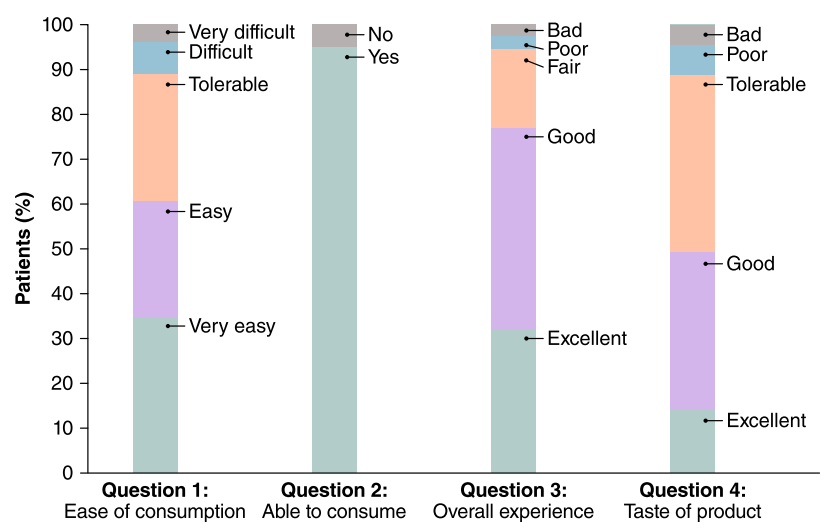

Fig. 1 Distribution of responses to the satisfaction survey questions. Items 1,3 , and 4 had five-point scales: very easy, easy, tolerable, difficult, very difficult; or excellent, good, fair/tolerable, poor, bad. Item 2 had a two-point scale: yes and no
Table 3 Comparison of total satisfaction score between patients administered $\mathrm{P} / \mathrm{MC}$ vs. 2-L PEG + bis

\begin{tabular}{llll}
\hline Items & P/MC & 2-L PEG + bis & $p$ value $^{\mathrm{a}}$ \\
\hline Total satisfaction score $^{\mathrm{b}}$ & & & $<0.0001$ \\
Median (interquartile range) & $50(50)$ & $120(75)$ & \\
Minimum, maximum & 0,250 & 0,400 & \\
\hline
\end{tabular}

$P / M C$ sodium picosulfate and magnesium citrate, $2-L P E G+$ bis $2-\mathrm{L}$ polyethylene glycol solution + two 5-mg bisacodyl tablets

${ }^{\text {a }}$ Based on the Wilcoxon rank sum test

b Sum of items 1-4. Survey items 1, 3, and 4 had five-point scales (very easy, easy, tolerable, difficult, very difficult; or excellent, good, fair/tolerable, poor, bad) and were assigned scores from $0-4$, with 0 representing most favorable (e.g. very easy or excellent) and 4 representing least favorable (e.g. very difficult or bad). Item 2 ("Were you able to consume the entire preparation as instructed?") was coded as 0 for yes and 1 for no. Raw scores of each of the four items were transformed to a range of $0-100$ (corresponding to $0-4$ on the original five-point scale or $0-1$ if yes/no) and summed up to a total score, yielding a total score range between 0 and 400, with lower scores indicating higher satisfaction

Domain 1 yielded a Cronbach's alpha of 0.79. The distribution of responses indicated a possible floor effect (denoting higher satisfaction) for three of four items related to satisfaction. For item 1 (difficulty in consuming the bowel-cleansing preparation), $35 \%$ of the subjects responded with the lowest possible score (i.e. 'very easy to use'); for item 2 (ability to consume the preparation as instructed), $95 \%$ of the subjects responded with 'yes'; and for item 3 (overall experience with the preparation), nearly $77 \%$ subjects responded with 'excellent' or 'good'. The analysis of predictive validity showed that total satisfaction scores were significantly better in patients who would accept the same bowel-preparation agent in a future colonoscopy compared with patients who would refuse it (median: 75 vs. 150, accept vs. refuse; $p<0.0001$; Wilcoxon rank sum test) (Table 4).

Among the study population that completed all survey questions, $960(80.3 \%)$ and $954(79.8 \%)$ patients were deemed responders using the Aronchick and Ottawa scales, respectively. According to either scale, responders had better total satisfaction scores compared with nonresponders [median: 75 vs. 100, responders vs. nonresponders for both the Aronchick scale (Table 5) and the Ottawa scale (Table 6)]; however, the differences according to either efficacy scale were not statistically significant (Table 4).

\section{Discussion}

Overall patient satisfaction regarding bowel-cleansing preparations is an important component in the CRC screening process as it may play a role in ensuring that the preparation is successfully consumed as instructed. Despite 
Table 4 Predictive validity of the patient satisfaction survey

Table 5 Satisfaction score and responders via the Aronchick scale

Table 6 Satisfaction score and responders via the Ottawa scale

\begin{tabular}{|c|c|c|c|c|c|}
\hline \multirow[t]{2}{*}{ Item } & \multicolumn{4}{|c|}{ Total satisfaction score, ${ }^{\mathrm{a}}$ median } & \multirow[t]{2}{*}{$p$ value $^{\mathrm{b}}$} \\
\hline & Accept & Refuse & Responder & Nonresponder & \\
\hline Likely to accept vs. refuse future colonoscopy & 75 & 150 & & & $<0.0001$ \\
\hline Responder vs. nonresponder (Aronchick scale) & & & 75 & 100 & 0.7984 \\
\hline Responder vs. nonresponder (Ottawa scale) & & & 75 & 100 & 0.4358 \\
\hline
\end{tabular}

${ }^{a}$ Sum of items 1-4. Survey items 1, 3, and 4 had five-point scales (very easy, easy, tolerable, difficult, very difficult; or excellent, good, fair/tolerable, poor, bad) and were assigned scores from $0-4$, with 0 representing most favorable (e.g. very easy or excellent) and 4 representing least favorable (e.g. very difficult or bad). Item 2 ("Were you able to consume the entire preparation as instructed?") was coded as 0 for yes and 1 for no. Raw scores of each of the four items were transformed to a range of 0-100 (corresponding to 0-4 on the original five-point scale or $0-1$ if yes/no) and summed up to a total score, yielding a total score range between 0 and 400, with lower scores indicating higher satisfaction

b Based on the Wilcoxon rank sum test

\begin{tabular}{|c|c|c|c|c|}
\hline Responder status & Survey measure & $n$ & Raw score [mean (SD)] & Median \\
\hline \multirow[t]{5}{*}{ No } & Easy/difficult & 232 & $1.19(1.07)$ & 1.00 \\
\hline & Able to consume the entire preparation & 233 & $0.05(0.21)$ & 0.00 \\
\hline & Overall experience & 232 & $1.00(0.92)$ & 1.00 \\
\hline & Taste of study preparation & 233 & $1.50(0.99)$ & 1.00 \\
\hline & Total satisfaction ${ }^{\mathrm{a}}$ & 231 & $97.5(74.43)$ & 100.0 \\
\hline \multirow[t]{5}{*}{ Yes } & Easy/difficult & 955 & $1.18(1.11)$ & 1.00 \\
\hline & Able to consume the entire preparation & 955 & $0.05(0.21)$ & 0.00 \\
\hline & Overall experience & 953 & $0.98(0.90)$ & 1.00 \\
\hline & Taste of study preparation & 956 & $1.53(0.96)$ & 2.00 \\
\hline & Total satisfaction ${ }^{\mathrm{a}}$ & 951 & $96.7(74.93)$ & 75.00 \\
\hline
\end{tabular}

$S D$ standard deviation

a Transformed score

\begin{tabular}{|c|c|c|c|c|}
\hline Responder status & Survey measure & $n$ & Raw score [mean (SD)] & Median \\
\hline \multirow[t]{5}{*}{ No } & Easy/difficult & 192 & $1.22(1.10)$ & 1.00 \\
\hline & Able to consume the entire preparation & 193 & $0.07(0.25)$ & 0.00 \\
\hline & Overall experience & 191 & $1.01(0.91)$ & 1.00 \\
\hline & Taste of study preparation & 193 & $1.51(0.96)$ & 2.00 \\
\hline & Total satisfaction ${ }^{\mathrm{a}}$ & 190 & $100.92(75.91)$ & 100.00 \\
\hline \multirow[t]{5}{*}{ Yes } & Easy/difficult & 992 & $1.18(1.11)$ & 1.00 \\
\hline & Able to consume the entire preparation & 992 & $0.04(0.20)$ & 0.00 \\
\hline & Overall experience & 991 & $0.98(0.91)$ & 1.00 \\
\hline & Taste of study preparation & 993 & $1.53(0.96)$ & 2.00 \\
\hline & Total satisfaction ${ }^{\mathrm{a}}$ & 989 & $96.26(74.58)$ & 75.00 \\
\hline
\end{tabular}

$S D$ standard deviation

${ }^{a}$ Transformed score

its importance, until recently no standardized survey was available to specifically measure patient satisfaction in bowel-cleansing preparations before colonoscopy [23]. We report that Domain 1 of the satisfaction survey administered in the two SEE CLEAR clinical trials exhibits internal consistency reliability. The Cronbach's alpha reliability coefficient derived in our study is similar to coefficients of $0.60-0.78$ reported by Sint Nicolaas and colleagues [23] for the five modules of a survey designed to assess patient experience with colonoscopy. We also found 
that Domain 1 of the satisfaction survey is able to predict patients' willingness to accept the same bowel preparation in the future.

An updated literature review revealed two scales developed to assess patients' overall satisfaction with endoscopy or to measure and improve the quality of endoscopy: a modified Group Health Association of America nine-item survey [24] and the Global Rating Scale (GRS) of the Royal College of Physicians Joint Advisory Group on GI Endoscopy [25], respectively. The GRS has four primary measures/domains: clinical quality, quality of patient experience, training, and workforce [25]. Of note, neither measure directly addresses patients' satisfaction and/or tolerance of bowel-cleansing preparation [23, 2528]. Patel and colleagues have recently reported the development and validation of a nine-item tolerability questionnaire in patients who underwent bowel preparation for colonoscopy [29]. Although no data are yet available using this questionnaire, the authors hypothesize a relationship may exist between bowel preparation tolerance and bowel cleanse quality. In our study, we did not observe any difference in total patient satisfaction scores between responders and nonresponders; however, significantly better satisfaction scores were found in patients who reported they would accept the same bowel preparation for a future colonoscopy. Similarly, Sint Nicolaas and colleagues reported that lower satisfaction due to a burdensome bowel preparation decreased a patient's willingness to repeat the procedure in the future [23].

Possible floor effects were observed in three of the four items in Domain 1. Several observations can be made to explain this finding. Items selected for this portion of the survey were assembled with the express purpose of measuring satisfaction in patients who willingly enrolled in a clinical trial and were fully aware of their need for colonoscopy. Thus, a uniform distribution of scores along the possible range of responses is highly unlikely. More importantly, the satisfaction survey was constructed to measure one domain (dimension) related to the patient's satisfaction with the bowel-preparation process. Theoretically, the floor and ceiling effects may not be as exaggerated in a general population survey, but this is not feasible here because the responses are skewed based on actual consumption of the colonoscopy preparation. Moreover, the observation that three of the four items in Domain 1 had a floor effect conservatively biased the results. Because a lower score denotes higher satisfaction, expanding the range on the satisfaction side would result in higher overall satisfaction scores.

The ability of a patient to completely consume the bowel preparation and its accompanying fluids is a key factor in achieving a high-quality colon cleansing and a successful colonoscopy. It stands to reason that patients with better satisfaction would be more compliant with ingesting the entire bowel preparation, which presumably would achieve better colon cleansing. However, our ability to assess this based on results from SEE CLEAR I and II $[10,11]$ is limited for two reasons. First, in these trials, there was a considerable floor effect in three of four survey items, with the majority of study patients providing favorable responses to the survey questions regardless of the bowel-cleansing preparation they received. Second, $99.3 \%$ and $91.1 \%$ of patients were able to ingest the entire $\mathrm{P} / \mathrm{MC}$ and $\mathrm{PEG}+$ bis preparation, respectively, resulting in a high compliance rate, and the rate of successful cleansing was $83.6 \%$ and $77.1 \%$ for patients administered P/MC and PEG + bis, respectively, using the Aronchick scale. Because of the disproportionate number of subjects considered responders, the difference in satisfaction scores between responders and nonresponders did not reach statistical significance.

An additional limitation of our analysis was that the patient satisfaction survey was not validated against an existing validated measure. During the design of the studies, a literature search failed to find any existing validated measure of patient satisfaction for bowel preparation prior to colonoscopy. Accordingly, the current analysis used the patient's self-reported willingness to ask for the same preparation at a future colonoscopy as a proxy measure of satisfaction. Additionally, studies with greater diversity in bowel preparation agents will be needed to more fully characterize patient satisfaction in patients preparing for colonoscopy.

Based on the short duration of the two trials investigated here, we cannot directly speak to the long-term benefit of appropriate screening in terms of minimizing the incidence of colon cancer. However, it could be argued that the potential long-term beneficial impact of the appropriate screening and bowel-cleansing preparation should not be ignored, given that the removal of precancerous adenomatous polyps during colonoscopy has been cited as one of the factors leading to a steady decline in CRC incidence over the past 30 years [30]. Bowel preparations that allow for better visualization will facilitate the detection and removal of adenomatous polyps, and patient compliance when taking a bowel preparation will have a favorable impact on this overall surveillance process.

\section{Conclusions}

The patient satisfaction survey measure used in the SEE CLEAR I and II trials was found to be reliable and valid. Overall, subjects who were more satisfied with their bowelcleansing preparation were more likely to accept the same preparation in the future. 
Acknowledgments The authors would like to thank Morris Barocas, MD, for reviewing an earlier draft of this manuscript. Editorial support was provided by The Curry Rockefeller Group, LLC. Financial support for editorial assistance was provided by Ferring Pharmaceuticals Inc.

\section{Compliance with Ethical Standards}

Funding This study was supported by a contract from Ferring Pharmaceuticals Inc., to Hind T. Hatoum \& Company. The authors had full control of all the primary data and findings, and the results are presented without any oversight or interference from the sponsor of the work.

Author contributions Hind T. Hatoum participated in analyzing and interpreting the data and drafting the manuscript; Swu-Jane Lin participated in analyzing the data and drafting the manuscript; Raymond E. Joseph participated in planning the study, collecting the data, and editing the manuscript; and David N. Dahdal participated in interpreting the data and drafting the manuscript.

Conflicts of interest Hind T. Hatoum is a paid consultant to Ferring Pharmaceuticals Inc.; Swu-Jane Lin is a consultant to Hind T. Hatoum \& Company; and Raymond E. Joseph and David N. Dahdal are employees of Ferring Pharmaceuticals Inc.

Ethical approval All procedures performed in studies involving human participants were in accordance with the ethical standards of the institutional and/or national research committee and the 1964 Helsinki declaration and its later amendments or comparable ethical standards.

Informed consent Informed consent was obtained from all individual participants included in the study.

Open Access This article is distributed under the terms of the Creative Commons Attribution-NonCommercial 4.0 International License (http://creativecommons.org/licenses/by-nc/4.0/), which permits any noncommercial use, distribution, and reproduction in any medium, provided you give appropriate credit to the original author(s) and the source, provide a link to the Creative Commons license, and indicate if changes were made.

\section{References}

1. Rex DK, Schoenfeld PS, Cohen J, Pike IM, Adler DG, Fennerty $\mathrm{MB}$, et al. Quality indicators for colonoscopy. Gastrointest Endosc. 2015;81:31-53.

2. Müller AD, Sonnenberg A. Prevention of colorectal cancer by flexible endoscopy and polypectomy. A case-control study of 32,702 veterans. Ann Intern Med. 1995;123:904-10.

3. Müller AD, Sonnenberg A. Protection by endoscopy against death from colorectal cancer. A case-control study among veterans. Arch Intern Med. 1995;155:1741-8.

4. Baxter NN, Goldwasser MA, Paszat LF, Saskin R, Urbach DR, Rabeneck L. Association of colonoscopy and death from colorectal cancer. Ann Intern Med. 2009;150:1-8.

5. Gaglia A, Papanikolaou IS, Veltzke-Schlieker W. New endoscopy devices to improve population adherence to colorectal cancer prevention programs. World J Gastrointest Endosc. 2010;2:244-51.

6. Perri F, Iacobellis A, Gentile M, Tumino E, Andriulli A. The intelligent, painless, "germ-free" colonoscopy: a Columbus' egg for increasing population adherence to colorectal cancer screening? Dig Liver Dis. 2010;42:839-43.

7. McLachlan SA, Clements A, Austoker J. Patients' experiences and reported barriers to colonoscopy in the screening context: a systematic review of the literature. Patient Educ Couns. 2012;86:137-46.

8. Aharony L, Strasser S. Patient satisfaction: what we know about and what we still need to explore. Med Care Rev. 1993;50:49-79.

9. Chartier L, Arthurs E, Sewitch MJ. Patient satisfaction with colonoscopy: a literature review and pilot study. Can J Gastroenterol. 2009;23:203-9.

10. Rex DK, Katz PO, Bertiger G, Vanner S, Hookey LC, Alderfer V, et al. Split-dose administration of a dual-action, low-volume bowel cleanser for colonoscopy: the SEE CLEAR I study. Gastrointest Endosc. 2013;78:132-41.

11. Katz PO, Rex DK, Epstein M, Grandhi NK, Vanner S, Hookey LC, et al. A dual-action, low-volume bowel cleanser administered the day before colonoscopy: results from the SEE CLEAR II study. Am J Gastroenterol. 2013;108:401-9.

12. Rostom A, Jolicoeur E. Validation of a new scale for the assessment of bowel preparation quality. Gastrointest Endosc. 2004;59:482-6.

13. DiPalma JA, McGowan J, Cleveland MV. Clinical trial: an efficacy evaluation of reduced bisacodyl given as part of a polyethylene glycol electrolyte solution preparation prior to colonoscopy. Aliment Pharmacol Ther. 2007;26:1113-9.

14. Jung B, Lannerstad O, Pahlman L, Arodell M, Unosson M, Nilsson E. Preoperative mechanical preparation of the colon: the patient's experience. BMC Surg. 2007;7:5.

15. El-Dika S, Mahl T, Mehboob S, Miqdadi J, Heels-Ansdell D, Handley B, et al. Is blinding the endoscopists to bowel preparations in randomized-controlled trials a reality? Cancer Detect Prev. 2006;30:552-9.

16. Kastenberg D, Barish C, Burack H, Dalke DD, Duckor S, Putnam $\mathrm{W}$, et al. Tolerability and patient acceptance of sodium phosphate tablets compared with 4-L PEG solution in colon cleansing: combined results of 2 identically designed, randomized, controlled, parallel group, multicenter phase 3 trials. J Clin Gastroenterol. 2007;41:54-61.

17. Aronchick CA, Lipshutz WH, Wright SH, Dufrayne F, Bergman G. A novel tableted purgative for colonoscopic preparation: efficacy and safety comparisons with Colyte and Fleet PhosphoSoda. Gastrointest Endosc. 2000;52:346-52.

18. Carmines EG, Zeller RA. Reliability and validity assessment. London: SAGE Publications; 1979.

19. Nunnally JC, Bernstein IH. Psychometric theory. 3rd ed. New York: McGraw-Hill; 1994.

20. Kline P. Handbook of psychological testing. 2nd ed. London: Routledge; 1999.

21. Fredheim OM, Borchgrevink PC, Saltnes T, Kaasa S. Validation and comparison of the health-related quality-of-life instruments EORTC QLQ-C30 and SF-36 in assessment of patients with chronic nonmalignant pain. $\mathrm{J}$ Pain Symptom Manage. 2007:34:657-65.

22. Terwee CB, Bot SD, de Boer MR, van der Windt DA, Knol DL, Dekker J, et al. Quality criteria were proposed for measurement properties of health status questionnaires. J Clin Epidemiol. 2007;60(1):34-42.

23. Sint Nicolaas J, de Jonge V, Korfage IJ, Ter Borg F, Brouwer JT, Cahen DL, et al. Benchmarking patient experiences in colonoscopy using the Global Rating Scale. Endoscopy. 2012;44:462-72.

24. Yacavone RF, Locke GR 3rd, Gostout CJ, Rockwood TH, Thieling S, Zinsmeister AR. Factors influencing patient satisfaction with GI endoscopy. Gastrointest Endosc. 2001;53:703-10. 
25. Royal College of Physicians Joint Advisory Group on GI Endoscopy. JAG Accreditation System and Endoscopy Global Rating Scale (GRS). https://www.jagaccreditation.org/. Accessed 19 Nov 2015.

26. Khalid-de Bakker CA, Jonkers DM, Hameeteman W, de Ridder RJ, Masclee AA, Stockbrugger RW. Opportunistic screening of hospital staff using primary colonoscopy: participation, discomfort and willingness to repeat the procedure. Digestion. 2011;84:281-8.

27. Bowles CJ, Leicester R, Romaya C, Swarbrick E, Williams CB, Epstein O. A prospective study of colonoscopy practice in the UK today: are we adequately prepared for national colorectal cancer screening tomorrow? Gut. 2004;53:277-83.

28. Wexner SD, Garbus JE, Singh JJ. A prospective analysis of 13,580 colonoscopies. Reevaluation of credentialing guidelines. Surg Endosc. 2001;15:251-61.

29. Patel M, Staggs E, Thomas CS, Lukens F, Wallace M, Almansa C. Development and validation of the Mayo Clinic Bowel Prep Tolerability Questionnaire. Dig Liver Dis. 2014;46(9):808-12.

30. Neugut AI, Lebwohl B. Screening for colorectal cancer: the glass is half full. Am J Public Health. 2009;99:592-4. 